\title{
Contributions of cultivar shift, management practice and climate change to maize yield in North China Plain in 1981-2009
}

\author{
Dengpan Xiao ${ }^{1,2,3} \cdot$ Fulu Tao ${ }^{1,4}$
}

Received: 19 October 2014 /Revised: 1 November 2015 / Accepted: 2 November 2015 / Published online: 20 November 2015

(C) ISB 2015

\begin{abstract}
The impact of climate change on crop yield is compounded by cultivar shifts and agronomic management practices. To determine the relative contributions of climate change, cultivar shift, and management practice to changes in maize (Zea mays L.) yield in the past three decades, detailed field data for 1981-2009 from four representative experimental stations in North China Plain (NCP) were analyzed via model simulation. The four representative experimental stations are geographically and climatologically different, represent the typical cropping system in the study area, and have more complete weather/crop records for the period of 1981-2009. The results showed that while the shift from traditional to modern cultivar increased yield by $23.9-40.3 \%$, new fertilizer management increased yield by $3.3-8.6 \%$. However, the trends in climate variables for 1981-2009 reduced maize yield by 15$30 \%$ in the study area. Among the main climate variables, solar radiation had the largest effect on maize yield, followed by temperature and then precipitation. While a significant decline in solar radiation in 1981-2009 (maybe due to air pollution) reduced yield by $12-24 \%$, a significant increase in temperature
\end{abstract}

Fulu Tao

taofl@igsnrr.ac.cn

1 Key Laboratory of Land Surface Pattern and Simulation, Institute of Geographical Sciences and Natural Resources Research, Chinese Academy of Sciences, Beijing 100101, China

2 Institute of Geographical Sciences, Hebei Academy of Sciences, Shijiazhuang 050011, China

3 Center for Agricultural Resources Research, Institute of Genetics and Developmental Biology, Chinese Academy of Sciences, Shijiazhuang 050021, China

4 Natural Resources Institute Finland (Luke), FI-01301 Vantaa, Finland reduced yield by 3-9 \%. In contrast, a non-significant increase in precipitation during the maize growth period increased yield by $0.9-3 \%$ at three of the four investigated stations. However, a decline in precipitation reduced yield by $3 \%$ in the remaining station. The study revealed that although the shift from traditional to modern cultivars and agronomic management practices contributed most to the increase in maize yield, the negative impact of climate change was large enough to offset 46$67 \%$ of the trend in the observed yields in the past three decades in NCP. The reduction in solar radiation, especially in the most critical period of maize growth, limited the process of photosynthesis and thereby further reduced maize yield.

Keywords Adaptation - Agronomic practice $\cdot$ Maize yield . Negative impact $\cdot$ Climate change

\section{Introduction}

Climate change has had major impacts on crop production at regional, national, and even global scales (Xiong et al. 2007; Lobell et al. 2011; Brown 2013). The impacts of climate change on crop yield in the past several decades were confounded by shifts of cultivars and agronomic management practices (Liu et al. 2010; Xiao and Tao, 2014). In order to accelerate understanding of climate change impacts and develop effective adaptation options, it is important to disentangle the roles of crop varieties, management practices, and climate change in historical crop yield change (Zheng et al. 2011; Xiao and Tao 2014).

The North China Plain (NCP) is one of the main agricultural production regions in China, with winter wheat (Triticum aestivum $\mathrm{L}$.) and summer maize (Zea mays $\mathrm{L}$.) crop rotation as the most typical cropping system (Tao et al. 2006). NCP accounts for some $50 \%$ of wheat and $33 \%$ of maize production 
in China, contributing immensely to food security in the country (Wang et al. 2012). In spite of this, the region is highly vulnerable to changing climatic factors such as increasing temperature, decreasing solar radiation, and worsening water shortage (Tao et al. 2006; Mo et al. 2009; Liu et al. 2010; Xiao and Tao 2014).

Several studies show that among cultivated staple food crops in the region, summer maize is the most vulnerable to climate variability and climate change (Tao and Zhang 2011; Chen et al. 2012; Zhang et al. 2014, 2015). Other studies also suggest that warming climate trends in the past several decades have had negative effects on maize production in the region (Liu et al. 2010; Chen et al. 2010). Generally, warming climate accelerates phenological development, shortens the crop growth period, and reduces the duration of photosynthesis and biomass accumulation (Xiao et al. 2013; 2015). Also, decreasing trends in solar radiation and precipitation limit maize growth and yield (Mo et al. 2009; Liu et al. 2010; Tao and Zhang 2011). Irrespectively, maize yield has increased in the last several decades in NCP (Tao et al. 2015). The change in yield is attributed to the combined effects of climate change, cultivar shift, and improved agronomic management practices (Liu et al. 2010; Wang et al. 2012; Chen et al. 2012).

There are several methods to evaluate the impact of various agronomic and climatic factors on crop yield. As field/ laboratory experiments can capture the effects of these factors on crop productivity, so also can crop models characterize the dynamics of plant growth and development. Unlike field experiments, however, crop models are relatively simple and cost-effective in evaluating the effects of crop cultivar, field management, and climate change (Wilcox and Makowski 2014). In this study, detailed field data (for 1981-2009) from four experimental stations in the NCP are used in combination with model simulation to determine (1) the relative contributions of cultivar shift and agronomic management to maize yield and (2) the impact of the changes in major climatic variables (temperature, solar radiation, and precipitation) on maize yield in the NCP region.

\section{Materials and methods}

\section{Study site}

The NCP study area, which includes portions of Hebei, Henan, and Shandong provinces and the whole of Beijing and Tianjin municipalities, is a major winter wheat and summer maize production region in China (Xiao and Tao 2014). Aeolian loam, the main soil type, occurs widely in river floodplains in the region. The monsoon precipitation is unevenly distributed, with over $70 \%$ occurring in the summer period from July through September. The mean precipitation is 500 $600 \mathrm{~mm}$ year $^{-1}$ against the high crop evapotranspiration (ET) of $800-900 \mathrm{~mm}$ year $^{-1}$. In the intensive winter wheat and summer maize double-cropping system, summer maize is cultivated from the start of June to the end of September (Xiao et al. 2015).

Data for this study were collected from four agrometeorological experiment stations, including Huanghua station $(\mathrm{HH})$ in Hebei Province, Xinxiang (XX) and Nanyang (NY) stations in Henan Province, and Laiyang station (LY) in Shandong Province (Fig. 1). General information on the crops and stations used in the study is summarized in Table 1. Although all lie in a typical summer maize cultivation zone (representative of the typical double-cropping system in the plain), the selected stations are geographically and climatologically different. The stations are also more complete in terms of recorded weather/crop data for the period 19812009.

\section{Climate and maize field experiment data}

Daily minimum (Tmin) and maximum (Tmax) temperatures, sunshine hours, and precipitation (Prec) for the period 19812009 were obtained from the Chinese Meteorological Administration (CMA). Daily solar radiation (Rad) was calculated from sunshine duration observations in the four stations using the Angstrom-Prescott (A-P) equation (Angstrom 1924; Prescott 1940) as

$\operatorname{Rad}=\left(a+b \frac{n}{N}\right) R_{a}$

where $R_{a}$ is extraterrestrial $\operatorname{Rad}\left(\mathrm{MJ} \mathrm{m}^{-2} \mathrm{~d}^{-1}\right) ; a$ and $b$ are the A-P coefficients; and $n$ and $N$ are, respectively, actual and theoretical sunshine durations. In this study, the $a$ and $b$ coefficients for the investigated stations were calibrated using observed radiation (Tao et al. 2014).

Maize phenological data, including sowing date, anthesis date, maturity date, cultivar type, aboveground dry matter (biomass), grain yield, 100-grain weight (1-GW), and management practice for 1981-2009, were obtained from field experiments in the four CMA agro-meteorological stations. The experimental crop management practices were either the same as or slightly better than the traditional practices at local areas. The maize cultivars were drawn from typical cultivars cultivated by local farmers in the region. In the study area, a new maize cultivar is adopted after every $3-5$ years. Fertilization and irrigation were repeatedly done during the cultivation seasons. With the exception of Huanghua station (which was kept under rain-fed conditions), irrigation was generally conducted about two times per year (one after sowing and the other at grain filling) in the other three stations. Fertilizer was also applied two times per year (one at sowing and the other at jointing). Pesticides were used to control pests and diseases during the cultivation season. 
Fig. 1 Referenced map showing the locations of North China Plain in China and that of the four investigated agro-meteorological experimental stations in the plain

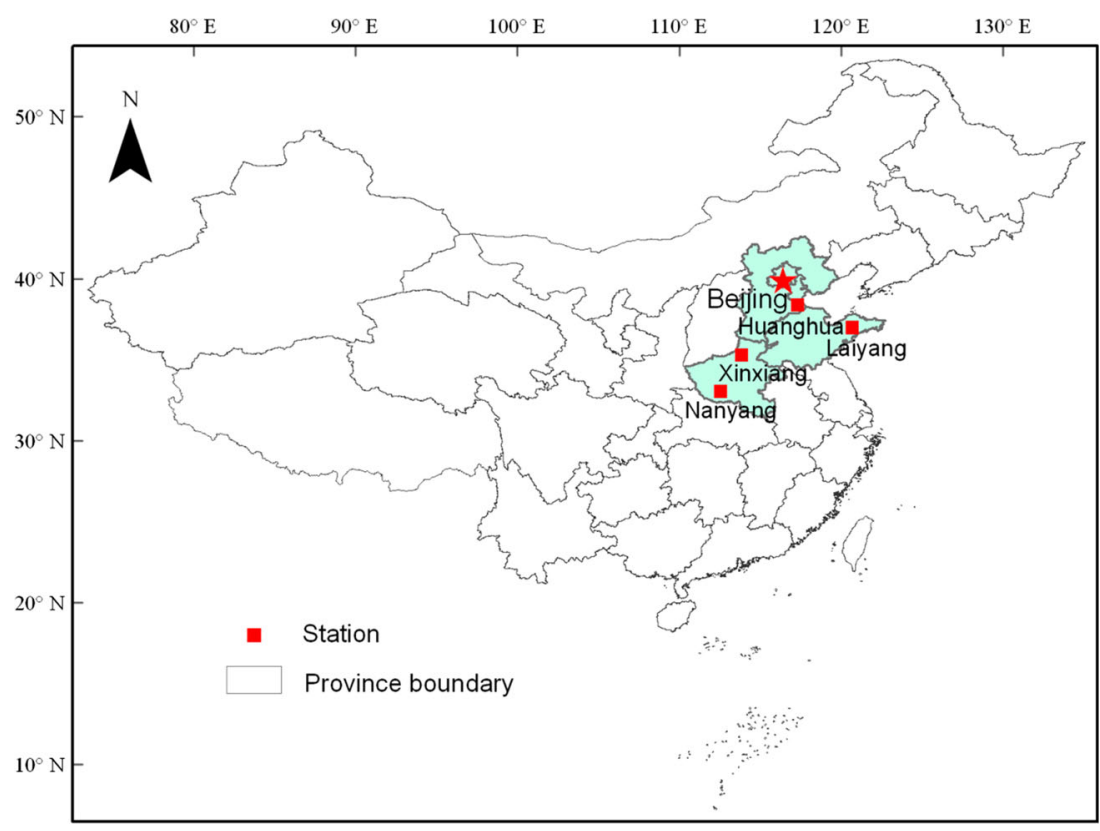

\section{APSIM-Maize calibration and validation}

The Agricultural Production Systems Simulator (APSIM) is a cropping system simulation model developed by the agricultural production systems research unit of Australia. It is a componentdriven model that concurrently runs several modules including crop growth, crop development, soil water, and nitrogen dynamics (Keating et al. 2003). APSIM simulates phenological processes, biomass accumulation and partitioning, leaf area index (LAI), as well as root, stem, leaf, and grain growth in daily time step from sowing to maturity. In its genetic crop module, APSIM uses genetic coefficients for the duration of each growth phase, photoperiod sensitivity, grain size, and grain-filling rate. Daily solar radiation, precipitation, and maximum/minimum air temperatures are the minimum weather input requirements of the model. APSIM is widely used in Australia, the USA, Netherlands, North Africa, China, and elsewhere around the globe (Asseng et al. 2000; Chen et al. 2010; Liu et al. 2012; Xiao and Tao 2014).

In this study, the typically cultivated cultivars in each of the four stations in 1981-2005 (cultivar-80) and 2005-2009
Table 1 General geographical, climatic, and agronomic data for four representative stations in maize-growing regions in North China Plain

\begin{tabular}{lllll}
\hline Stations & Huanghua & Xinxiang & Nanyang & Laiyang \\
\hline Latitude $\left({ }^{\circ} \mathrm{N}\right)$ & 38.37 & 35.32 & 33.03 & 36.97 \\
Longitude $\left({ }^{\circ} \mathrm{E}\right)$ & 117.35 & 113.88 & 112.58 & 120.73 \\
Altitude $(\mathrm{m})$ & 6.6 & 72.7 & 129.2 & 54.4 \\
Crop data period & $1981-2009$ & $1981-2009$ & $1981-2009$ & $1981-2009$ \\
Weather data period & $1981-2009$ & $1981-2009$ & $1981-2009$ & $1981-2009$ \\
Soil $(0-30 \mathrm{~cm})$ & & & & \\
$\quad$ Soil type & Loam & Loam & Loam & Silt loam \\
$\quad$ Soil organic matter $\left(\mathrm{g} \mathrm{kg}{ }^{-1}\right)$ & 12.6 & 16.8 & 22.3 & 11.3 \\
$\quad$ Soil total N $\left(\mathrm{g} \mathrm{kg}^{-1}\right)$ & 0.74 & 1.05 & 1.29 & 0.73 \\
Climate & & & & 12.8 \\
$\quad$ Annual mean temperature $\left({ }^{\circ} \mathrm{C}\right)$ & 13.5 & 15.0 & 15.7 & 14.0 \\
$\quad$ Annual mean solar radiation $\left(\mathrm{MJ} \mathrm{m}{ }^{-2}\right)$ & 13.5 & 13.3 & 12.2 & 653.1 \\
$\quad$ Annual total precipitation $(\mathrm{mm})$ & 534.2 & 548.1 & 778.7 & Groundwater \\
Management & & & & NPK \\
$\quad$ Irrigation water source & Rain fed & Groundwater & Groundwater \\
$\quad$ Fertilizer type & NPK & NPK & NPK & \\
\hline
\end{tabular}

Note that NPK represents chemical fertilizer composed of nitrogen, phosphorous, and potassium, respectively 


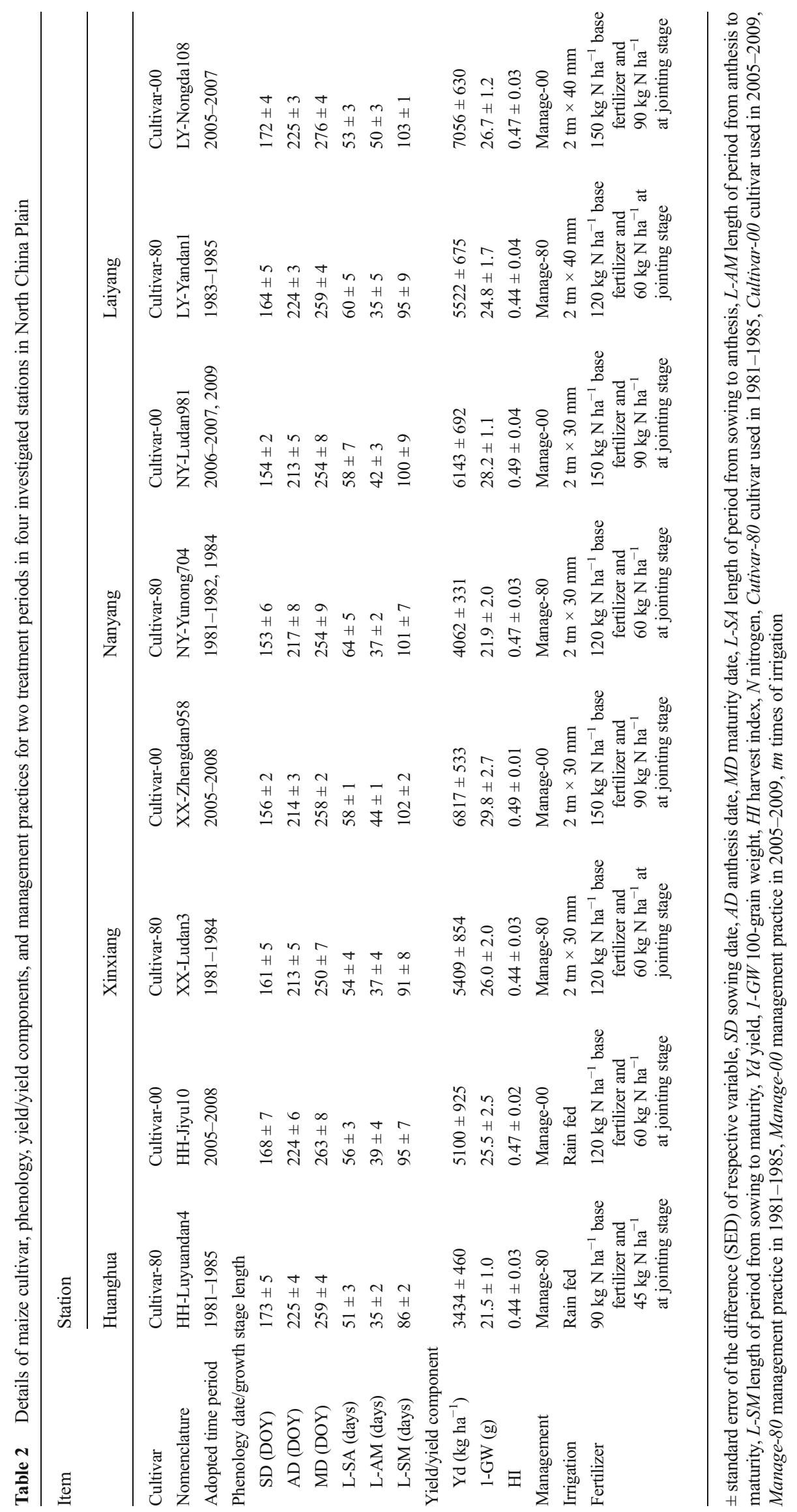


(cultivar-00) were used. Then, field observations for 19811985 and 2005-2009 (Table 2) were used to respectively calibrate and validate the model. The dataset included phenological date, growth period length [e.g., sowing to anthesis (L-SA) and anthesis to maturity (L-AM)], yield and yield components (e.g., 1-GW and HI), and management practices. As listed in Table 3, APSIM-Maize requires several fieldbased cultivar-specific genetic parameters. The coefficients tt_emerg_to_endjuv, tt_flower_to_maturity, and tt_flower_to_start_grain determine phenological development, and photoperiod_slope denotes sensitivity of the maize cultivar to the photoperiod during the end of the juvenile phase to floral initiation. Then, the coefficients grain gth rate and head_grain_no_max determine grain yield. For 1981-1985 and 2005-2009, 1-2 years of field observation data were used for calibration and the other 3-4 years of field observation data used for validation of the model. The coefficients of cultivar- 80 and cultivar- 00 listed in Table 3 represent the observed changes in the field.

The model performance was evaluated based on the slope, coefficient of determination $\left(R^{2}\right)$, root mean square error (RMSE), and agreement index (D) (Willmott 1982) of observed and simulated values.

$D=1-\left[\sum_{i=1}^{N}\left(P_{i}-O_{i}\right)^{2} / \sum_{i=1}^{N}\left(\left|P_{i}^{\prime}\right|-\left|O_{i}^{\prime}\right|\right)^{2}\right] \quad 0 \leq D \leq 1$

where $P_{i}$ is simulated values; $O_{i}$ is observed values; $N$ is number of values; and $P_{i}^{\prime}=P_{i}-\bar{O}$ and $O_{i}^{\prime}=O_{i}-\bar{O} ; \bar{O}$ are average observed values. $D$ is a better indicator of model performance, particularly in relation to the $1: 1$ line of best fit. A $D$ value close to 1 indicates low model bias while a $D$ value of 0 indicates no relationship between observed and simulated variables (Willmott 1982).

\section{Cultivar, management, and yield relationship}

In the four investigated stations, fertilizer management (e.g., fertilizer application rate) increased substantially during the period 1981-2009 while other traditional agronomic management practices (e.g., tillage and irrigation) changed little. Thus, an increase in fertilizer application rate was treated as improved management practice.

Three data-driven modeling experiments (i.e., M1, M2, and M3) were used to evaluate the impacts of cultivar shift and improved management practices on maize yield and yield components. Traditional cultivar (cultivar-80) and traditional management (management80) conditions were used to run experiment M1 for 1981-1985 agronomic conditions. Modern cultivar (cultivar-00) and management-80 conditions were used to run experiment M2. Then, experiment M3 was run on cultivar-00 and improved management (management00) for 2005-2009 agronomic conditions. In other words, experiments M1 and M2 had the same fertilization management practice but different cultivars. However, experiments M2 and M3 had the same cultivar but different fertilization management practices. The different experiments were then used to isolate the impacts of cultivar shift and fertilization management on maize yield and yield components by comparing the simulation results.

The impacts of cultivar shift on maize yield and yield components were determined by comparing experiments M1 and M2. The contribution of cultivar shift to maize yield was calculated as

$$
C R_{C C}(Y)=\left(Y_{M 2}-Y_{M 1}\right) / Y_{M 1} \times 100 \%
$$

Table 3 Parameters of two representative crop cultivars used in APSIM-Maize model simulation in North China Plain

\begin{tabular}{|c|c|c|c|c|c|c|c|c|}
\hline \multirow[t]{2}{*}{ Parameter } & \multicolumn{8}{|l|}{ Station } \\
\hline & Huanghua & & Xinxiang & & Nanyang & & Laiyang & \\
\hline Cultivar & Cultivar-80 & Cultivar-00 & Cultivar- 80 & Cultivar-00 & Cultivar-80 & Cultivar-00 & Cultivar-80 & Cultivar-00 \\
\hline $\begin{array}{l}\text { tt_emerg_to_endjuv (thermal time from } \\
\text { emergence to end of juvenile stage }\left({ }^{\circ} \mathrm{C} \text { day)) }\right.\end{array}$ & 160 & 180 & 170 & 210 & 210 & 180 & 200 & 160 \\
\hline $\begin{array}{l}\text { tt flower_to maturity (thermal time from } \\
\left.\text { flowering to maturity }\left({ }^{\circ} \mathrm{C} \text { day }\right)\right)\end{array}$ & 570 & 660 & 620 & 740 & 600 & 760 & 550 & 740 \\
\hline $\begin{array}{l}\text { tt_flower_to_start grian (thermal time from } \\
\text { flowering to start of grain-filling }\left({ }^{\circ} \mathrm{C} \text { day)) }\right.\end{array}$ & 130 & 130 & 100 & 100 & 120 & 130 & 100 & 120 \\
\hline $\begin{array}{l}\text { grain_gth_rate (potential grain-filling rate } \\
\left.\left(\text { mg grain weight } \text { day }^{-1}\right)\right)\end{array}$ & 8.5 & 10.5 & 11.0 & 11.5 & 10.0 & 11.5 & 10.0 & 11.0 \\
\hline $\begin{array}{l}\text { head_grain_no_max (potential maximum } \\
\text { grain size) }\end{array}$ & 560 & 680 & 600 & 690 & 600 & 650 & 600 & 690 \\
\hline $\begin{array}{l}\text { photoperiod slope (required thermal time change } \\
\text { for floral initiation per hour photoperiod } \\
\left.\text { increase }\left({ }^{\circ} \mathrm{Ch}^{-1}\right)\right)\end{array}$ & 15.0 & 16.0 & 15.0 & 16.0 & 16.0 & 16.0 & 16.0 & 16.0 \\
\hline
\end{tabular}

Cutivar-80 cultivar used in 1981-1985, Cultivar-00 cultivar used in 2005-2009 
where $C R_{C C}(Y)[\%]$ is the percent ratio of cultivar shift contribution to yield and $Y_{M 1}$ and $Y_{M 2}[\mathrm{~kg}]$ are simulated yields of experiments $\mathrm{M} 1$ and $\mathrm{M} 2$, respectively.

Similarly, the contributions of improved management to maize yield and yield components were determined by comparing experiments M2 and M3. Hence, the contribution of improved management to maize yield was calculated as

$C R_{I M}(Y)=\left(Y_{M 3}-Y_{M 2}\right) / Y_{M 2} \times 100 \%$

where $C R_{I M}(Y)[\%]$ is the percent ratio of improved management contribution to yield and $Y_{M 3}[\mathrm{~kg}]$ is the simulated yield of experiment M3.

The combined impacts of crop cultivar shift and improved management practices on maize yield/yield components in 1981-2009 were determined by comparing experiments M1 and M3. The contribution of cultivar shift and improved management to maize yield was calculated as

$$
C R_{\mathrm{CCIM}}(Y)=\left(Y_{M 3}-Y_{M 1}\right) / Y_{M 1} \times 100 \%
$$

where $C R_{C C I M}(Y)[\%]$ is the percent ratio of the contribution of cultivar shift and improved management to yield. A similar procedure was used to calculate the contributions of cultivar shift and/or improved management practice to harvest index (HI), 100-grain weight (1-GW), and water use efficiency (WUE).

\section{Cultivar sensitivity to climatic variables}

To investigate the sensitivities of the different maize cultivars to climate change, the APSIM-Maize model was first run on observed weather data for 1981-2009. It was next run on the same weather data but for increasing daily temperatures of 1,2 , and $3{ }^{\circ} \mathrm{C}$. The model was again run on the same weather data but for varying solar radiation and precipitation conditions of $-10,-20$, and $-30 \%$. To determine the sensitivity of maize cultivars to the climatic variables, the results of the three model runs (for temperature, solar radiation, and precipitation) were separately compared with those of observed weather conditions in 1981-2009.

\section{Effect of climate change variable on yield}

Temporal trends (1981-2009) in climate variables (e.g., Tmax, Tmin, Rad, and Prec) at annual and seasonal cycles of maize growth in the four investigated stations were determined from linear regression analysis. Then, the significance of the trends was determined from the two-tailed $t$ test analysis.

Four data-driven simulations were conducted to determine the effects of the change in each climate variable on maize yield for the period 1981-2009 (Table 4). To determine the impact of a given climate variable (i.e., temperature) on yield, a 29-year simulation (1981-2009) was run 29 times. In each 29-year simulation, observed daily data for the given variable (i.e., temperature) for 1981-2009 were used and daily data for all other input variables (e.g., solar radiation and precipitation) held constant for a given year (e.g., 1981) (Table 4). This resulted in 29 (daily temperature data for 1981-2009) $\times 29$ (daily solar radiation and precipitation data for each year in 1981-2009), giving 841 simulation results. Finally, the impact of the changes in each climate variable (e.g., temperature, precipitation, and solar radiation) on maize yield was estimated by computing simulated mean yield trend for 1981-2009 (Xiao and Tao 2014). Finally, the total impact of all the climate variables on yield was divided by the total observed yield trend (1981-2009) to determine the effect of climate change on yield trend for the investigated period.

\section{Results}

\section{Observed phenological and yield changes}

Based on field observation data, different phenological dates were noted for maize cultivar- 80 and cultivar- 00 . Compared with cultivar- 80 , the sowing date of cultivar-00 was 5 days earlier in Huanghua and Xinxiang stations. However, sowing dates were delayed in Nanyang and Laiyang stations and by up to 8 days in Laiyang station. There was no obvious change in anthesis date, except for Nanyang station where anthesis occurred 4 days earlier. Maturity dates were delayed by 4,8 , and 15 days, respectively, in Huanghua, Xinxiang, and Laiyang stations (Table 2). Thus, the duration of growth of cultivar-00 from sowing to maturity was longer than that of cultivar-80 in all the stations, except Nanyang station. While the period from sowing to anthesis was prolonged in Huanghua and Xinxiang stations, it shortened in Nanyang and Laiyang stations. In contrast, the period from anthesis to maturity of cultivar-00 was 4-15 days longer than that of cultivar- 80 in all the stations (Table 2).

Based on field data for 1981-2009, the observed yield of cultivar-00 was higher than that of cultivar- 80 in all the stations (Table 2). Furthermore, the 100-grain weight (1-GW) and harvest index (HI) of cultivar-00 were higher than those of cultivar-80 (Table 2).

\section{APSIM-Maize model calibration and validation}

Overall, there was a good agreement between the modelsimulated and field-observed dates of anthesis and maturity for all the investigated stations (Fig. 2a, b). On average, the difference between simulated and observed dates of anthesis and maturity was less than 5 days. Both $R^{2}$ and $D$ values for the simulated anthesis and maturity dates exceeded 0.88 , suggesting good agreement between the values. Also, the 
Table 4 Detailed weather data used in APSIM-Maize model simulation of the impact of climatic variables on maize yield in North China Plain

\begin{tabular}{llll}
\hline Climate variable & Temperature & Radiation & Precipitation \\
\hline ME_all & $1981-2009$ & $1981-2009$ & $1981-2009$ \\
ME_temp & $1981-2009$ & Repeat of single year & Repeat of single year \\
ME_rad & Repeat of single year & $1981-2009$ & Repeat of single year \\
ME_prec & Repeat of single year & Repeat of single year & $1981-2009$ \\
\hline
\end{tabular}

ME_all, ME_temp, ME_rad, and ME_prec, respectively, denote simulated impacts for all the climatic variables, temperature, solar radiation, and precipitation on maize yield

simulated grain yield was in good agreement with the observed one (Fig. 2c). The average difference between simulated and observed yields was less than $500 \mathrm{~kg} \mathrm{ha}^{-1}$ (less than $10 \%$ of observed values), with $R^{2}$ and $D$ for simulated yield exceeding 0.93 . In addition, simulated aboveground dry matter (biomass) agreed well with the field-observed value (Fig. 2d). Although the corresponding RMSE was higher than $1200 \mathrm{~kg} \mathrm{ha}^{-1}, \mathrm{R}^{2}$ and $D$ values exceeded 0.88 . Thus, the results of the APSIM model simulation of maize growth phenology and yield were reliable and thus applicable.

\section{Cultivar and management effect on yield}

For the period 1981-2009, cultivar shifts and improved fertilizer management practices, respectively, increased maize yield by $23.9-40.3$ and $3.3-8.6 \%$, respectively (Table 5). New cultivars and new fertilization methods together enhanced yield by $28.0-52.4 \%$. In comparison with cultivar-80, 1-GW, HI, and WUE of cultivar-00 increased on average by $16.1,12.8$, and $18.9 \%$, respectively. Also, improved fertilization management practices on average
Fig. 2 Plots of validation analysis of the APSIM-Maize model simulation against fieldobserved data for anthesis date (a), maturity date (b), grain yield (c), and biomass (d) in the investigation stations in North China Plain. DOY is day of year; dashed lines and solid lines are, respectively, the 1:1 line and regression trend line; and $* *$ is significant trend at $1 \%$ probability level
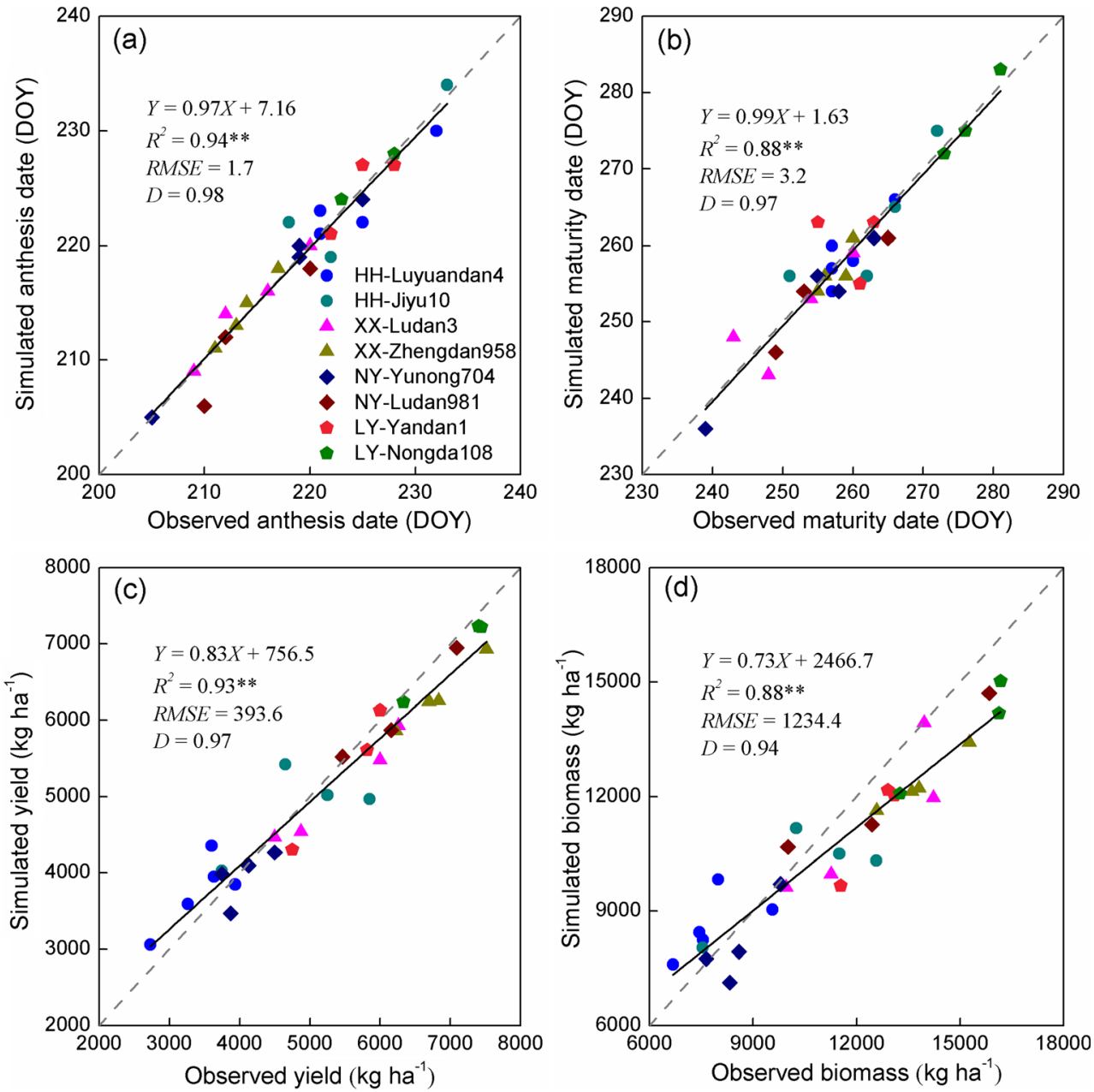
Table 5 Detailed contributions (\%) of cultivar shifts and improved fertilization management practices to yield (Yd), 100-grain weight (1-GW), harvest index (HI), and water use efficiency (WUE) of maize in North China Plain for the period 1981-2009

\begin{tabular}{|c|c|c|c|c|c|}
\hline Station & Huanghua & Xinxiang & Nanyang & Laiyang & Average \\
\hline $\mathrm{CR}_{\mathrm{CC}}(\mathrm{Yd})$ & $40.3 \pm 23.4$ & $23.9 \pm 14.3$ & $32.9 \pm 16.9$ & $28.5 \pm 16.7$ & $31.4 \pm 7.0$ \\
\hline $\mathrm{CR}_{\mathrm{IM}}(\mathrm{Yd})$ & $8.6 \pm 6.8$ & $3.3 \pm 0.6$ & $4.9 \pm 1.6$ & $3.5 \pm 1.9$ & $5.1 \pm 2.5$ \\
\hline $\mathrm{CR}_{\mathrm{CCIM}}(\mathrm{Yd})$ & $52.4 \pm 23.5$ & $28.0 \pm 14.9$ & $39.4 \pm 17.6$ & $33.0 \pm 21.4$ & $38.2 \pm 10.6$ \\
\hline $\mathrm{CR}_{\mathrm{CC}}(1-\mathrm{GW})$ & $18.1 \pm 13.3$ & $15.6 \pm 10.1$ & $19.5 \pm 12.3$ & $11.2 \pm 7.8$ & $16.1 \pm 3.6$ \\
\hline $\mathrm{CR}_{\mathrm{IM}}(1-\mathrm{GW})$ & $8.1 \pm 6.6$ & $1.7 \pm 0.5$ & $3.9 \pm 1.8$ & $3.7 \pm 2.1$ & $4.4 \pm 2.7$ \\
\hline $\mathrm{CR}_{\mathrm{CCIM}}(1-\mathrm{GW})$ & $27.7 \pm 11.1$ & $17.6 \pm 12.2$ & $24.2 \pm 15.3$ & $15.3 \pm 10.6$ & $21.2 \pm 5.7$ \\
\hline $\mathrm{CR}_{\mathrm{CC}}(\mathrm{HI})$ & $18.5 \pm 11.4$ & $14.1 \pm 9.3$ & $7.2 \pm 5.9$ & $11.3 \pm 8.3$ & $12.8 \pm 4.8$ \\
\hline $\mathrm{CR}_{\mathrm{IM}}(\mathrm{HI})$ & $3.5 \pm 3.2$ & $1.9 \pm 1.3$ & $1.9 \pm 1.3$ & $2.9 \pm 1.7$ & $2.6 \pm 0.8$ \\
\hline $\mathrm{CR}_{\mathrm{CCIM}}(\mathrm{HI})$ & $22.7 \pm 11.8$ & $16.3 \pm 9.5$ & $9.2 \pm 8.1$ & $14.5 \pm 10.5$ & $15.7 \pm 5.6$ \\
\hline $\mathrm{CR}_{\mathrm{CC}}$ (WUE) & $24.1 \pm 18.6$ & $9.5 \pm 4.7$ & $23.4 \pm 14.5$ & $18.6 \pm 13.4$ & $18.9 \pm 6.7$ \\
\hline $\mathrm{CR}_{\mathrm{IM}}$ (WUE) & $6.0 \pm 4.9$ & $1.4 \pm 0.3$ & $2.8 \pm 2.3$ & $2.4 \pm 0.7$ & $3.2 \pm 2.0$ \\
\hline $\mathrm{CR}_{\text {CCIM }}$ (WUE) & $31.5 \pm 19.5$ & $11.0 \pm 5.9$ & $26.9 \pm 14.7$ & $21.4 \pm 14.1$ & $22.7 \pm 8.8$ \\
\hline
\end{tabular}

Note that " \pm " is the standard error of the difference (SED) of respective variables. $\mathrm{CR}_{\mathrm{CC}}(\mathrm{Yd}), \mathrm{CR}_{\mathrm{CC}}(1-\mathrm{GW}), \mathrm{CR}_{\mathrm{CC}}(\mathrm{HI})$, and $\mathrm{CR} \mathrm{RC}_{\mathrm{CC}}(\mathrm{WUE})$, respectively, denote the contributions of cultivar shift to maize yield, 100-grain weight (1-GW), harvest index (HI), and water use efficiency (WUE); $\mathrm{CR}_{\mathrm{IM}}$ (Yield), $\mathrm{CR}_{\mathrm{IM}}(1-\mathrm{GW}), \mathrm{CR}_{\mathrm{IM}}(\mathrm{HI})$, and $\mathrm{CR}_{\mathrm{IM}}$ (WUE), respectively, denote the contributions of improved fertilization management practice to maize yield, 1-GW, HI, and WUE. Also $\mathrm{CR}_{\mathrm{CCIM}}$ (Yield), $\mathrm{CR}_{\mathrm{CCIM}}(1-\mathrm{GW}), \mathrm{CR}_{\mathrm{CCIM}}(\mathrm{HI})$, and $\mathrm{CR}_{\mathrm{CCIM}}$ (WUE) denote the contributions of cultivar shift and improved fertilization management practice to maize yield, 1-GW, HI, and WUE

increased 1-GW, HI, and WUE, respectively, by 4.4, 2.6, and $3.2 \%$. The combined effect of cultivar shift and improved fertilization on average increased 1-GW, HI, and WUE by $21.2,15.7$, and $22.7 \%$, respectively (Table 5).

\section{Cultivar sensitivity to climate variable}

Cultivar- 80 and cultivar- 00 were similar in terms of sensitivity to the investigated climate variables. For both cultivars, yield decreased with increasing temperature or with decreasing solar radiation and precipitation (Fig. 3). In terms of yield, the cultivars were more sensitive to change in solar radiation and temperature than to change in precipitation. Under increasing temperature and decreasing solar radiation (Fig. 3), the decrease in yield of cultivar- 00 was less than that of cultivar80. This suggested that modern cultivars were more adaptable to climate change than traditional cultivars. However, yield of cultivar- 00 was more sensitive to changes in precipitation than yield of cultivar-80 (Fig. 3). This further suggested that modern cultivars favor higher precipitation conditions.

\section{Climate change and climate variable-driven yield}

A warming trend was noted for the maize growth period in 1981-2009 in all the investigated stations (Table 6). The rate of increase in Tmin was greater than that in Tmax in the stations. While solar radiation decreased in all the stations, it was significant in Huanghua, Xinxiang, and Laiyang stations. Furthermore, the rate of decrease in solar radiation at seasonal cycle (maize growing season) was higher than that at annual cycle. However, the rate of increase in temperature (both Tmin and Tmax) at seasonal cycle (maize growth season) was lower than that at the annual cycle. While precipitation increased insignificantly in Xinxiang, Nanyang, and Laiyang stations, it only slightly decreased in Huanghua station.

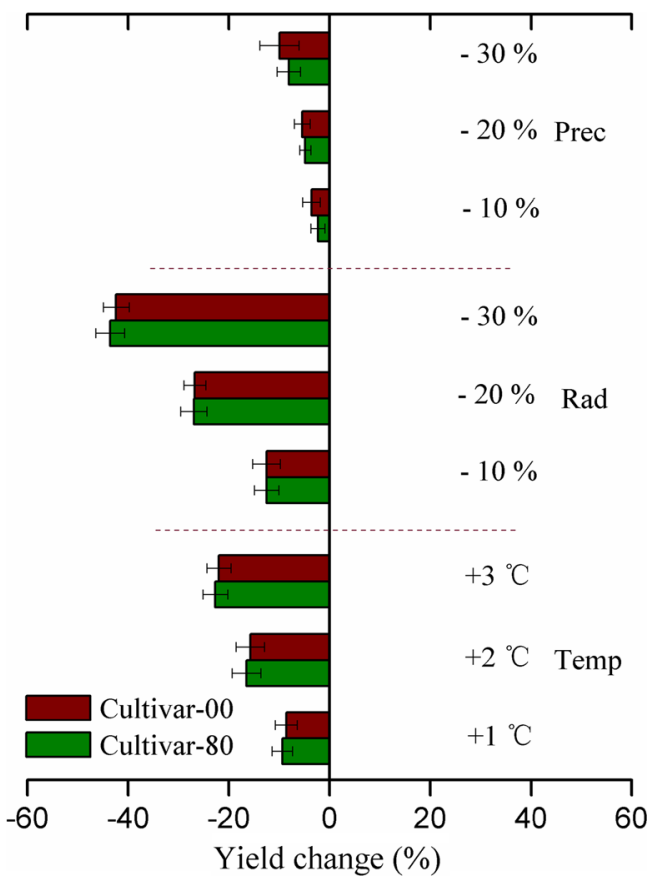

Fig. 3 Sensitivities (in terms of yield) of the two representative maize cultivars to temperature (Temp), solar radiation $(\mathrm{Rad})$, and precipitation (Prec) in the four investigated stations in North China Plain. The error bar is the $95 \%$ confidence interval 
Table 6 Trends (1981-2009) in solar radiation (Rad), maximum temperature (Tmax), minimum temperature (Tmin), and precipitation (Prec) at annual and seasonal (maize growth season) cycles in four investigated stations in North China Plain

\begin{tabular}{|c|c|c|c|c|c|c|c|c|c|}
\hline \multirow[t]{2}{*}{ Station } & \multirow[t]{2}{*}{ Period } & \multicolumn{2}{|l|}{$\operatorname{Rad}$} & \multicolumn{2}{|l|}{ Tmax } & \multicolumn{2}{|l|}{ Tmin } & \multicolumn{2}{|l|}{ Prec } \\
\hline & & $\begin{array}{l}\text { Mean } \\
\left(\mathrm{MJ} \mathrm{m}^{-2}\right)\end{array}$ & $\begin{array}{l}\text { Trend } \\
\left(\mathrm{MJ} \mathrm{m}^{-2} 10 \mathrm{a}^{-1}\right)\end{array}$ & $\begin{array}{l}\text { Mean } \\
\left({ }^{\circ} \mathrm{C}\right)\end{array}$ & $\begin{array}{l}\text { Trend } \\
\left({ }^{\circ} \mathrm{C} 10 \mathrm{a}^{-1}\right)\end{array}$ & $\begin{array}{l}\text { Mean } \\
\left({ }^{\circ} \mathrm{C}\right)\end{array}$ & $\begin{array}{l}\text { Trend } \\
\left({ }^{\circ} \mathrm{C} 10 \mathrm{a}^{-1}\right)\end{array}$ & $\begin{array}{l}\text { Mean } \\
(\mathrm{mm})\end{array}$ & $\begin{array}{l}\text { Trend } \\
\left(\mathrm{mm} \mathrm{10a}^{-1}\right)\end{array}$ \\
\hline \multirow[t]{2}{*}{ Huanghua } & Annual & 13.5 & $-0.45^{* *}$ & 18.6 & $0.36^{*}$ & 8.4 & $0.81 * *$ & 534.2 & 6.7 \\
\hline & Maize growth period & 16.8 & $-1.02 * *$ & 30.3 & 0.28 & 21.2 & $0.57 * *$ & 361.3 & -12.9 \\
\hline \multirow[t]{2}{*}{ Xinxiang } & Annual & 13.3 & $-0.37^{*}$ & 20.0 & $0.37 * *$ & 10.0 & $0.64^{* *}$ & 548.1 & 20.0 \\
\hline & Maize growth period & 16.8 & $-0.65^{*}$ & 30.6 & 0.23 & 21.6 & $0.36^{* *}$ & 353.9 & 26.7 \\
\hline \multirow[t]{2}{*}{ Nanyang } & Annual & 12.2 & -0.17 & 20.5 & $0.46^{* *}$ & 10.8 & $0.59 * *$ & 778.7 & 14.3 \\
\hline & Maize growth period & 15.7 & $-0.57 *$ & 30.6 & 0.19 & 22.0 & $0.37 * *$ & 460.3 & 22.9 \\
\hline \multirow[t]{2}{*}{ Laiyang } & Annual & 14.0 & $-0.38^{* *}$ & 18.2 & $0.31 *$ & 7.3 & $0.62 * *$ & 653.1 & 57.2 \\
\hline & Maize growth period & 16.5 & $-0.88 * *$ & 28.7 & 0.03 & 19.2 & $0.43 * *$ & 463.2 & 61.9 \\
\hline
\end{tabular}

*Significant trend at the $5 \%$ probability level; **Significant trend at the $1 \%$ probability level

With increasing temperature during the maize growing season, yield of both cultivars declined insignificantly $(p>0.05)$ in all four stations. Warming climate in the last three decades reduced yield by $0.1-0.3 \%$ per year. For all the investigated stations, the decrease in solar radiation in 1981-2009 reduced yield of the two maize cultivars by $0.4-0.8 \%$ per year (Table 7). The decline in yield due to decreasing solar radiation was slightly higher for the traditional cultivars (cultivar80) than for the modern cultivars (cultivar-00). Due to change in precipitation during the maize growing period, yield of both cultivars slightly increased at Xinxiang, Nanyang, and Laiyang stations, and decreased at Huanghua station.

The combined effects of the changes in the climatic variables in 1981-2009 reduced maize yield by $0.5-1.0 \%$ per year (Table 7). Although the impacts of climate change on yield of the two maize cultivars were similar, cultivar-00 was more suitable than cultivar-80 to climate change. Field-observed maize yield increased significantly $\left(58.1-78.3 \mathrm{~kg} \mathrm{ha}^{-1}\right.$ per year or $1.1-$ $1.5 \%$ per year) in the four investigated stations for the period 1981-2009 (Table 7). It then suggested that the estimated impact of climate change on yield accounted for $-66.7,-46.2,-50.0$, and $-54.5 \%$ of the observed yield trend in 1981-2009 in Huanghua, Xinxiang, Nanyang, and Laiyang stations, respectively (Table 7).

\section{Discussions}

\section{Agro-climatic effects on maize yield in 1981-2009}

Crop yield is generally influenced by several factors, including cultivar type, management practice, and climatic conditions

Table 7 Impacts of the trends (1981-2009) in all the climatic variables combined and separately in temperature, solar radiation, and precipitation on yields $\left(\mathrm{kg} \mathrm{ha}^{-1}\right.$ year $\left.^{-1}\right)$ of two maize cultivars in North China Plain

\begin{tabular}{llllll}
\hline Variable & & Huanghua & Xinxiang & Nanyang & Laiyang \\
\hline Cultivar-80 & ME_all & $-34.1 *(-1.0 \%)$ & $-31.1 *(-0.6 \%)$ & $-26.6^{*}(-0.7 \%)$ & $-33.8^{* *}(-0.6 \%)$ \\
& ME_temp & $-11.1(-0.3 \%)$ & $-12.3(-0.2 \%)$ & $-6.1(-0.2 \%)$ & $-8.4(-0.2 \%)$ \\
& ME_rad & $-27.8^{*}(-0.8 \%)$ & $-27.3 *(-0.5 \%)$ & $-21.6^{*}(-0.5 \%)$ & $-30.1 * *(-0.5 \%)$ \\
& ME_prec & $-2.7(-0.1 \%)$ & $3.6(0.1 \%)$ & $2.6(0.04 \%)$ & $1.6(0.03 \%)$ \\
Cultivar-00 & ME_all & $-36.5 *(-0.6 \%)$ & $-34.6^{*}(-0.5 \%)$ & $-29.1 *(-0.5 \%)$ & $-34.2 * *(-0.5 \%)$ \\
& ME_temp & $-14.6(-0.3 \%)$ & $-12.7(-0.1 \%)$ & $-7.6(-0.1 \%)$ & $-10.2(-0.1 \%)$ \\
& ME_rad & $-28.6 *(-0.5 \%)$ & $-30.2 *(-0.4 \%)$ & $-26.2 *(-0.4 \%)$ & $-31.5 * *(-0.4 \%)$ \\
& ME_prec & $-4.2(-0.1 \%)$ & $3.3(0.04 \%)$ & $3.0(0.04 \%)$ & $2.1(0.03 \%)$ \\
Trends in field observed yield & $58.1 * *(1.5 \%)$ & $78.3 *(1.3 \%)$ & $67.8^{* *}(1.4 \%)$ & $61.3 * *(1.1 \%)$ & $-54.5 \%$ \\
Estimated impacts of all climate variables & $-66.7 \%$ & $-46.2 \%$ & $-50.0 \%$ & &
\end{tabular}

ME_all, ME_temp, ME_rad and ME_prec are, respectively, estimated impacts of all climatic variables, temperature, solar radiation and precipitation on maize yield

*Significant trend at $5 \%$ probability level; **Significant trend at $1 \%$ probability level 
(Xiao and Tao 2014). A good understanding of how nonclimatic factors (such as cultivar shift and management practice) and climatic factors contribute to grain yield/yield components is essential for sustainable production strategies that enhance food security (Tao and Zhang 2010). It was noted that although shifts in cultivars and agronomic practices in 1981-2009 increased yield, climate change also reduced maize yield (Fig. 4). For instance, $\mathrm{Ci}$ et al. (2011) showed that the average gain in maize yield driven by genetic factors in the 1970s-2000s was $94.7 \mathrm{~kg} \mathrm{ha}^{-1}$ per year, $53 \%$ of which was attributed to breeding as newer hybrids increased maize resistance to compound stress. Chen et al. (2012) noted that major changes in maize varieties led to a significant yield increase in recent decades. Cultivar characteristics that contribute most to yield increase include longer anthesis-to-maturity (mainly grain-filling stage) duration, higher grain count per spike, and higher 1-GW, HI, and WUE, and higher resistance to biotic/abiotic stress (Tao and Zhang 2010; Zheng et al. 2011; Xiao et al. 2015). New cultivars were more resistant to climate change than old ones (Liu et al. 2010; Chen et al. 2012; Xiao and Tao 2014). Although our field data showed a significant increase in HI, Liu et al. (2010) noted no increase in maize HI in Nanyang station for recent decades. The discrepancy in the results of the contemporary studies could be due to the use of different data sources or crop cultivars.

Favorable agronomic management practices include shifts in sowing date, improved irrigation, fertilization management, and tillage conversion (Jin et al. 2012; Wang et al. 2012). Based on the field data, traditional agronomic management practices such as tillage and irrigation changed little in the investigated stations. However, fertilize management (e.g., fertilize application rate) changed significantly in the investigated period (Liu et al. 2003; Zhang 2008). Thus, the study focused mainly on the increase in fertilizer application rate. Although fertilizer use efficiency generally decreases with increasing application rate (Zhang et al. 2012), increasing use of nitrogen $(\mathrm{N})$ fertilizers notably increases crop yield ( $\mathrm{Lv}$ et al. 2011). Insect, disease, and weed infestations were neglected due to the continuous use of pesticides during the period of study (Xiao and Tao 2014).

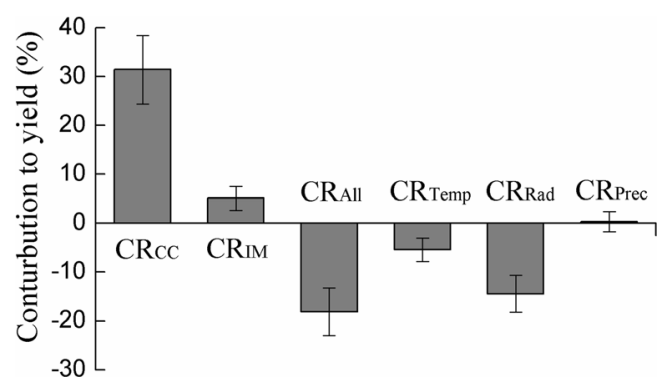

Fig. 4 Contributions (\%) of cultivar shift $\left(C R_{C C}\right)$, improved fertilizer management $\left(C R_{I M}\right)$, all climate variables $\left(C R_{A l l}\right)$, temperature $\left(C R_{\text {Temp }}\right)$, solar radiation $\left(C R_{\text {Rad }}\right)$, and precipitation $\left(C R_{\text {Prec }}\right)$ to maize yield in North China Plain in 1981-2009. The error bar is the $95 \%$ confidence interval

\section{Changes in climate variable and maize yield}

For the investigated climatic factors, the impact of solar radiation on maize yield was greater than that of temperature and precipitation. China, as one of the largest and most populated developing countries, is experiencing rapid economic growth. The intense human activity releases vast amounts of tiny particles and greenhouse gases into the atmosphere. The increase in aerosols in the atmosphere induces strong reflection of incoming solar radiation and rapid decline in solar radiation absorption (Wang and Yang 2014). Thus, a strong trend of decline in solar radiation has persisted in China since the 1960s (Che et al. 2005). Generally, low solar radiation during the time solar energy is most required could prevent photosynthesis and thereby cause further reduction in crop yield (Stansel 1975; Shuai et al. 2013). In this study, solar radiation decreased in all the four stations in 1981-2009, causing 0.4 $0.8 \%$ reduction in maize yield per year. The decline in yield due to the decline in solar radiation was slightly higher for the traditional cultivar (cultivar-80) than for the modern cultivar (cultivar-00).

The trend in warming climate has accelerated in NCP in the last several decades. This study suggested that the increase in temperature had a negative impact on maize yield and that warming climate in 1981-2009 reduced maize yield by $0.1-$ $0.3 \%$ per year. Warmer climate generally accelerated crop development and thereby shortened the duration of the maize growing season (Chen et al. 2010; Xiao et al. 2015). Furthermore, the impact of temperature on grain yield is especially notable when higher temperatures occur at flowering stage (Wheeler et al. 2000; Liu et al. 2010). In monsoon climate regions, precipitation can be critical for inter-annual variability in yield due to large fluctuations in precipitation (Zhang et al. 2015). In the long term, climate change could aggravate water scarcity and jeopardize sustainable agricultural production in NCP (Tao and Zhang 2011). For the period of study, the trend in precipitation during the maize growth period was insignificant. The yield of both maize cultivars (traditional and modern cultivar) increased slightly in Xinxiang, Nanyang, and Laiyang stations while it decreased slightly in Huanghua station.

\section{Conclusions}

This study used field data from four experimental stations for the period 1981-2009 along with APSIM-Maize model simulation to determine the relative contributions of climate variables, cultivar shifts, and management practices to maize yield in NCP. The climate variables investigated in the study include temperature, solar radiation, and precipitation, which had different but consistent impacts on maize yield in the study area in the past three decades. 
The study noted that modern cultivars and agronomic management practices contributed dominantly to changes in yield in the NCP. However, the negative effects of climate change were large enough to offset all significant gains in maize yield in 1981-2009. Among climatic factors, the effect of solar radiation on yield was greater than that of temperature and precipitation. Decreasing solar radiation and increasing temperature decreased maize yield while change in precipitation had a slight effect on maize yield.

Adaptation strategies including higher-heat-tolerant cultivars at grain-filling stage; longer anthesis-to-maturity duration cultivars; higher 1-GW, HI, and WUE cultivars; and cultivars with higher resistance to biotic/abiotic stress and improved agronomic management practices could offset the negative impacts of climate change on sustainable crop production in the NCP region and generally on food security in China.

Acknowledgments This study was supported by the National Natural Science Foundation of China (Nos. 41571088 and 41401104), Science and Technology Strategic Pilot Projects of the Chinese Academy of Sciences (No. XDA05090308), Natural Science Foundation of Hebei Province (D2015302017), China Postdoctoral Science Foundation (2015M570167), and Science and Technology Planning Project of Hebei Academy of Sciences (15101). Funding support by FACCE MACSUR project through the Finnish Ministry of Agriculture and Forestry is also gratefully acknowledged. We are thankful to the capable anonymous reviewers and editors who contributed invaluably by raising critical suggestions and remarks during the review phase of this publication.

\section{References}

Angstrom A (1924) Solar and terrestrial radiation. Q J Roy Meteor Soc 50:121-126

Asseng S, van Keulen H, Stol W (2000) Performance and application of the APSIM N-wheat model in the Netherlands. Eur J Agron 12:37-54

Brown I (2013) Influence of seasonal weather and climate variability on crop yields in Scotland. Int J Biometeorol 57:605-614

Che H, Shi G, Zhang X, Arimoto R, Zhao J, Xu L, Wang B, Chen Z (2005) Analysis of 40 years of solar radiation data from China, 1961-2000. Geophys Res Lett 32:L06803

Chen C, Wang E, Yu Q, Zhang Y (2010) Quantifying the effects of climate trends in the past 43 years (1961-2003) on crop growth and water demand in the North China Plain. Clim Chang 100:559-578

Chen G, Liu H, Zhang J, Liu P, Dong S (2012) Factors affecting summer maize yield under climate change in Shangdong Province in the Huanghuaihai Region of China. Int J Biometeorol 56:621-629

Ci X, Li M, Liang X, Xie Z, Zhang D, Li X, Lu Z, Ru G, Bai L, Xie C, Hao Z, Zhang S (2011) Genetic contribution to advanced yield for maize hybrids released from 1970 to 2000 in China. Crop Sci 51:1-8

Jin L, Cui H, Li B, Zhang J, Dong S, Liu P (2012) Effects of integrated agronomic management practices on yield and nitrogen efficiency of summer maize in North China. Field Crops Res 134:30-35

Keating BA, Carberry PS, Hammer GL, Porter ME, Robertson MJ, Holzworth D, Huth NI, Hargreaves JNG, Meinke H, Hochman Z, Mclean G, Verburg K, Snow V, Dimes JP, Silburn M, Wang E, Brown S, Bristow KL, Asseng S, Chapman S, McCown RL, Freebairn DM, Smith CJ (2003) An overview of APSIM, a model designed for farming systems simulation. Eur J Agron 18:267-288
Liu X, Ju X, Zhang F, Pan J, Christie P (2003) Nitrogen dynamics and budgets in a winter wheat-maize cropping system in the North China Plain. Field Crops Res 83:111-124

Liu Y, Wang E, Yang X, Wang J (2010) Contributions of climatic and crop varietal changes to crop production in the North China Plain, since 1980s. Glob Chang Biol 16:2287-2299

Liu Z, Yang X, Hubbard K, Lin X (2012) Maize potential yields and yield gaps in the changing climate of northeast China. Glob Chang Biol 18:3441-3454

Lobell DB, Bänziger M, Magorokosho C, Vivek B (2011) Nonlinear heat effects on African maize as evidenced by historical yield trials. Nat Clim Chang 1:42-45

Lv P, Zhang J, Liu W, Yang J, Su K, Liu P, Dong S, Li D (2011) Effects of nitrogen application on yield and nitrogen use efficiency of summer maize under super-high yield conditions. Plant Nutr Fertil Sci 17: 852-860(in Chinese with English abstract)

Mo X, Liu S, Lin Z, Guo R (2009) Regional crop yield, water consumption and water use efficiency and their responses to climate change in the North China Plain. Agric Ecosyst Environ 134:67-78

Prescott JA (1940) Evaporation from a water surface in relation to solar radiation. T Roy Soc South Aust 64:114-118

Shuai J, Zhang Z, Liu X, Chen Y, Wang P, Shi P (2013) Increasing concentrations of aerosols offset the benefits of climate warming on rice yields during 1980-2008 in Jiangsu Province, China. Reg Environ Chang 13:287-297

Stansel JW (1975) Effective utilization of sunlight. In: Texas Agricultural Experiment station, in cooperation with the U.S. Department of Agriculture. Six Decades of Rice Research in Texas Res Monogr 4:43-50

Tao F, Zhang Z (2010) Adaptation of maize production to climate change in North China Plain: quantify the relative contributions of adaptation options. Eur J Agron 33:103-116

Tao F, Zhang Z (2011) Impacts of climate change as a function of global mean temperature increase: maize productivity and water use in China. Clim Chang 105:409-432

Tao F, Yokozawa M, Xu Y, Hayashi Y, Zhang Z (2006) Climate changes and trends in phenology and yields of field crops in China, 19812000. Agric For Meteorol 13:82-92

Tao F, Zhang Z, Xiao D, Zhang S, Rotter RP, Shi W, Liu Y, Wang M, Liu F, Zhang H (2014) Responses of wheat growth and yield to climate change in different climate zones of China, 1981-2009. Agric For Meteorol 189-190:91-104

Tao F, Zhang S, Zhang Z, Rotter RP (2015) Temporal and spatial changes of maize yield potentials and yield gaps in the past three decades in China. Agric Ecosyst Environ 208:12-20

Wang Y, Yang Y (2014) China's dimming and brightening: evidence, causes and hydrological implications. Ann Geophys 32:41-55

Wang J, Wang E, Yang X, Zhang F, Yin H (2012) Increased yield potential of wheat-maize cropping system in the North China Plain by climate change adaptation. Clim Chang 113:825-840

Wheeler TR, Craufurd PQ, Ellis RH, Porter JR, Vara Prasad PV (2000) Temperature variability and the annual yield of crops. Agric Ecosyst Environ 82:159-167

Wilcox J, Makowski D (2014) A meta-analysis of the predicted effects of climate change on wheat yields using simulation studies. Field Crops Res 156:180-190

Willmott CJ (1982) Some comments on the evaluation of model performance. B Am Meteorol Soc 63:1309-1313

Xiao D, Tao F (2014) Contributions of cultivars, management and climate change to winter wheat yield in the North China Plain in the past three decades. Eur J Agron 52:112-122

Xiao D, Tao F, Liu Y, Shi W, Wang M, Liu F, Zhang S, Zhu Z (2013) Observed changes in winter wheat phenology in the North China Plain for 1981-2009. Int J Biometeorol 57:275-285

Xiao D, Qi Y, Shen Y, Tao F, Moiwo JP, Liu J, Wang R, Zhang H, Liu F (2015) Impact of warming climate and cultivar change on maize 
phenology in the last three decades in North China Plain. Theor Appl Climatol. doi:10.1007/s00704-015-1450-x

Xiong W, Matthews R, Holman I, Lin E, Xu Y (2007) Modeling China's potential maize production at regional scale under climate change. Clim Chang 85:433-451

Zhang F (2008) Nitrogen use efficiencies of major cereal crops in China and measures for improvement. Acta Pedol Sinica 45:915-924(in Chinese with English abstract)

Zhang F, Cui Z, Chen X, Ju X, Shen J, Chen Q, Liu X, Zhang W, Mi G, Fan M, Jiang R (2012) Integrated nutrient management for food security and environ-mental quality in China. Adv Agron 116:1-40
Zhang Z, Chen Y, Wang P, Zhang S, Tao F, Liu X (2014) Spatial and temporal changes of agro-meteorological disasters affecting maize production in China since 1990. Nat Hazards 71:2087-2100

Zhang H, Zhao X, Yin X, Liu S, Xue J, Wang M, Pu C, Lal R, Chen F (2015) Challenges and adaptations of farming to climate change in the North China Plain. Climatic Change doi:. doi:10.1007/s10584015-1337-y

Zheng T, Zhang X, Yin G, Wang L, Han Y, Chen L, Huang F, Tang J, Xia $X, H e$ Z (2011) Genetic gains in grain yield, net photosynthesis and stomatal conductance achieved in Henan Province of China between 1981 and 2008. Field Crops Res 122:225-233 